\title{
Spatial Analysis of Swine Influenza Virus in Pig Farms Based on Active Surveillance from 2016- 2017 in West Java Province, Indonesia
}

\author{
Nurhayati \\ Directorate of Animal Health, \\ Directorate General of Livestock and \\ Animal Health Services \\ Ministry of Agriculture \\ Jakarta, Indonesia \\ noe_drh@yahoo.com
}

Trian Mahawan

Disease Investigation Center Subang Directorate General of Livestock and Animal Health Services

Ministry of Agriculture

West Java, Indonesia

Farida C Zenal

Emergency Centre for Transboundary

Animal Diseases

Food and Agriculture Organization of

the United Nations

Jakarta, Indonesia

Mark Stevenson

Faculty of Veterinary and Agriculture Science

The University of Melbourne

Victoria, Australia
Ali Rizqi Arasyi

Emergency Centre for Transboundary Animal Diseases

Food and Agriculture Organization of the United Nations

Jakarta, Indonesia

ali.arasyi@gmail.com

Luuk Schoonman

Emergency Centre for Transboundary Animal Diseases

Food and Agriculture Organization of the United Nations

Jakarta, Indonesia

Katon D Kurniawan

Emergency Centre for Transboundary Animal Diseases

Food and Agriculture Organization of the United Nations

Jakarta, Indonesia

Sodirun

Disease Investigation Center Subang

Directorate General of Livestock and Animal Health Services Ministry of Agriculture West Java, Indonesia

\author{
Caitlin Pfeiferd \\ Faculty of Veterinary and Agriculture \\ Science \\ The University of Melbourne \\ Victoria, Australia
}

Fajar Sumping Tjaturrasa

Directorate of Animal Health, Directorate General of Livestock and

Animal Health Services

Ministry of Agriculture

Jakarta, Indonesia

Afrizal Panus

Disease Investigation Center Subang Directorate General of Livestock and Animal Health Services

Ministry of Agriculture

West Java, Indonesia

James McGrane

Emergency Centre for Transboundary Animal Diseases

Food and Agriculture Organization of the United Nations

Jakarta, Indonesia

\begin{abstract}
H1N1 swine flu virus still today in the world become threat for livestock and humans. This disease is fatal to human and has cause economic losses especially for pig farmers with $100 \%$ morbidity rate. The emergence and rapid spread of swine influenza virus (SIV) H1N1 in pig farms is closely related to increase in dense of pig populations and as a reservoir for genetically diverse influenza viruses with the potential infect to humans and backyard farming systems that allow possibility virus transmission from infected pig farm with SIV to the other pig farms. However, despite the high risk for pig farm and human health, control of SIV in Indonesia remains complex, unresolved and can cause severe economic impact on pig farming. The objectives of this study are to characterize the spatial distribution of SIV infection in pig farms in West Java Province and determine the exact pattern of spread from farm to farm and determine the effective strategy to prevent and control SIV disease using spatial analysis. The method used kernel density and spatial autocorrelation using Moran's I and Ripley's K-Function to analyze the SIV distribution pattern randomly, disperse or cluster over a range of distance. The data used from H1N1
\end{abstract}

surveillance profiling and result from 2016-2017 from Disease Investigation Center (DIC) Subang. in West Java province, SIV lab testing result and pig population, human population data. The result indicates one clustered district in Kuningan district and 3 non clustered (non-spatial autocorrelation) district in Bogor, Bekasi and Karawang District. Based on kernel density results show pig population density as a spatial risk factor with high density per sq $\mathbf{k m}$. Based on $\mathrm{k}$-function indicate to control program should extend to $2 \mathrm{~km}$ around the SIV positive farm especially in clustered disease area. This information also useful for disease policy makers for disease prevention and control program. If identified a case of SIV positive in pig farm location, surveillance efforts should extend to another pig farms a distance of $\mathbf{2 . 0 0 0}$ metres positive farm especially in clustered disease area.

Keywords-siv, kernel density, spatial autocorrelation, west java province. 


\section{INTERPRETATIVE SUMMARY}

H1N1 swine flu virus is a serious threat to livestock and human health. In West Java Province Indonesia in 2009 reported human cases infected by $\mathrm{H} 1 \mathrm{~N} 1$ virus infection and there are still reported farms infected with H1N1. The Studies on spatial analysis to identify the spread pattern of H1N1 swine flu virus between pig farm and risk of spread to human are still limited. This study is needed to determine appropriate control and prevention by disease policy maker to deal with the risk of SIV spread.

\section{INTRODUCTION}

Swine Influenza (swine flu) is a respiratory disease of pigs caused by type A influenza virus that regularly causes outbreaks of influenza in pigs. Swine flu viruses can cause high levels of illness in pig herds but cause few deaths in pigs. Swine influenza viruses can circulate among swine throughout the year. Swine flu viruses are thought to be spread among pigs mostly through close contact and possibly from contaminated objects moving between infected and uninfected pigs [4]. but most animals recover within 3-7 days. Fatality rate ranges from less than $1 \%$ to $4 \%$ [5]. Human infections with swine influenza viruses are occasionally reported, usually in persons who have direct contact with infected pigs and resembling seasonal influenza. Swine influenza viruses spread very rarely in human populations. most swine influenza in humans was associated with occupational exposure, such as workers in the pig or poultry industries. Most of the patients recovered swiftly and there were few fatalities. Swine influenza is not a foodborne disease. The risk of being infected with swine influenza viruses through the consumption of pork or pork products is negligible. Influenza viruses are generally restricted to the respiratory tract of pigs and are not detected in the muscle (meat) of pigs, even during acute illness [5].

Recently, swine flu cases are still reported in several region in Indonesia, particularly in backyard pig farms system with high densely pig farm location. The backyard pig farm system is common in Indonesia due to less costs for operational, no permanent pen required and feeding. High density of pig populations in densely populated environments and high density of human population creates the risk of spread from swine flu viruses between pig farms and to human and possible to spread through live pig movement (trading or pig collector activities). Disease associated with swine influenza virus (SIV) infection of pigs has been recognized as an important cause of economic loss to pig farmers [7]. There is also concern over the potential human health risks associated with porcine infection. Humans working in close contact with pigs have been reported to have increased likelihood of seropositivity to SIVs [8].

West Java province is the main supplier of pig carcass or pig live slaughter to the capital city of DKI (Special Capital Region) Jakarta. Therefore, DIC (Disease Investigation Center) Subang with FAO -ECTAD (Food and Agriculture Organization of the United Nations Emergency Centre for Transboundary Animal Diseases)
Indonesia chose to conduct pig farms profiling and swine flu surveillance in West Java province since 2016 - 2017. Based on profiling results on pig farms in West Java Province, total 364 respondents from pig farmers were interviewed covering Bekasi, Bogor, Karawang and Kuningan districts. The total population of live pigs in West Java Province reached 8,338 pigs.

The swine flu surveillance was conducted by taking samples from 175 total pig farms in four district of West Java province, which then tested for SIV in DIC Subang laboratory using ELISA test. Laboratory result point out that 54 pig farms of 175 sampling farms are infected H1N1. High densely of pig farm location possibly become a major problem for SIV spread and transmission. High number of morbidity rate or illness in pig farm can cause high economic losses to pig farmers. Studies of SIV distribution patterns based on spatial analysis are still limited. There is a need to conduct spatial analysis study to evaluate the spatial distribution of SIV positive cases in pig farms to support the SIV prevention and control effort. Moreover, it is useful to determine the distance affected area from SIV positive farm and identify the control program to reduce SIV cases in West Java province.

GIS (Geographic Information System)-based technology has been widely used in numerous epidemiology studies including in the field of swine influenza [1][2][3]. By combining GIS and spatial statistic, researchers and public health officers will have better understanding about the disease pattern which will assist in detecting high-risk area and formulate effective targeted intervention.

The objectives of this study are to characterize the spatial distribution of SIV infection in pig farms in West Java Province and determine the exact pattern of spread for disease control strategy using spatial analysis. The method used spatial autocorrelation model (Moran's I) to analyze the SIV distribution pattern randomly, disperse or cluster where the closest area that has the same value indicates a spatial clustering.

\section{MATERIALS AND METHODS}

\section{A. Study Area}

This study was conducted in four districts in West Java province which cover 20 percent of total West Java province area. West Java itself is a province that situated in the intermediate position $5^{0} 50^{\prime}-7^{0} 50^{\prime}$ south latitude and $104^{0} 48^{\prime}-108^{0} 48^{\prime}$ east longitude. The total area of West Java is more than $35,000 \mathrm{~km}^{2}$. The study area is selected because they are the only districts from 27 district in total which have pig population. Moreover, it has direct administrative boundary adjacency to Jakarta which could cause severe cases. A map of study area is shown in Fig. 1. All of four districts in the study area, Kuningan is the only district that did not have direct administrative boundary adjacency with the other districts. Moreover, the pig farms in Kuningan are concentrated in Cigugur sub-district where the pig population outnumber pig population. 


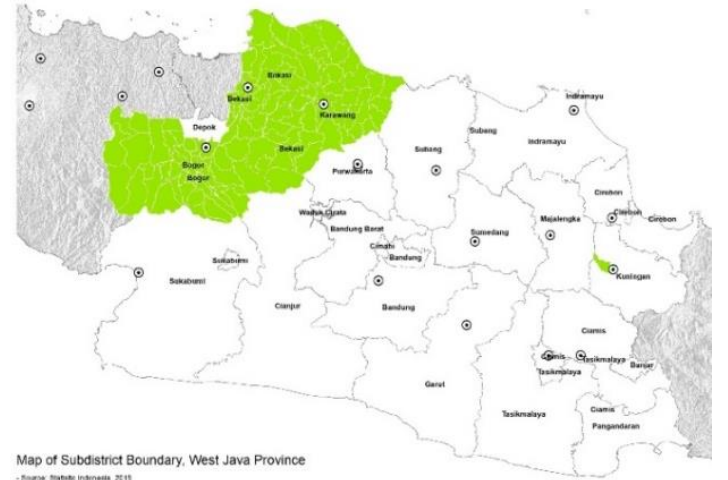

Fig. 1. Map of Study Area in West Java Province

Based on BPS data, in 2017, 10.02 million of human population in study area* or 22.7 percent from total human population of West Java Province which susceptible to SIV risk. From Fig. 2, it can be concluded that most of the population in West Java province is concentrated in Bandung, Bogor, Depok and Bekasi regions.

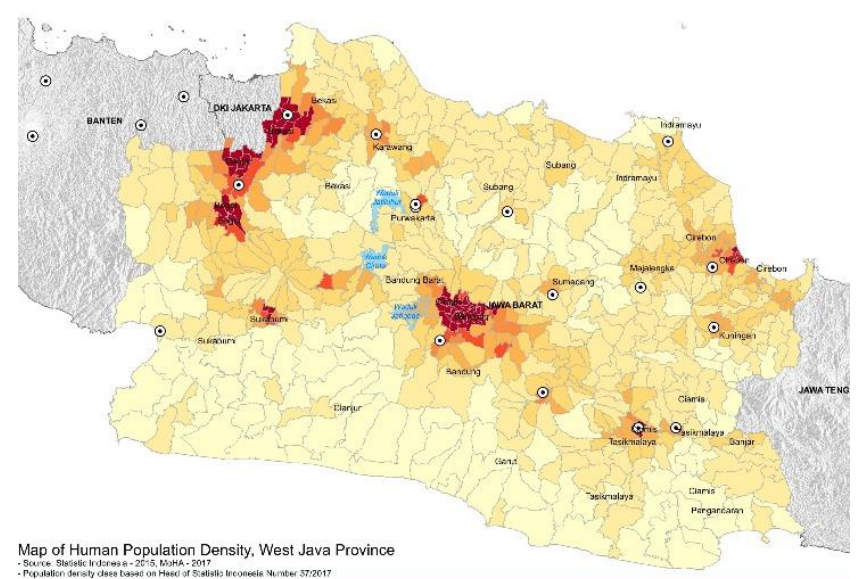

(2)

Fig. 2. Map of Human Population Density in West Java Province

\section{B. Data Collection}

The primary data that used in this study is profiling data (spatial data point) of pig farm for SIV Surveillance 20162017 conducted by DIC Subang and laboratory data result from infected and non-infected farm locations in West Java province based on ELISA test result from DIC Subang. The sample took from total 175 pig farms using Risk Based Surveillance method. Latitude and longitude coordinates were obtained by plotting the farm location using handheld Global Positioning System (GPS) receiver. Fig. 3 illustrate the profiling and sampling farm distribution in the study area, where in Kuningan sub-district, the pig farms clustered in Sukamulya, Cisantana, and Cigugur village.

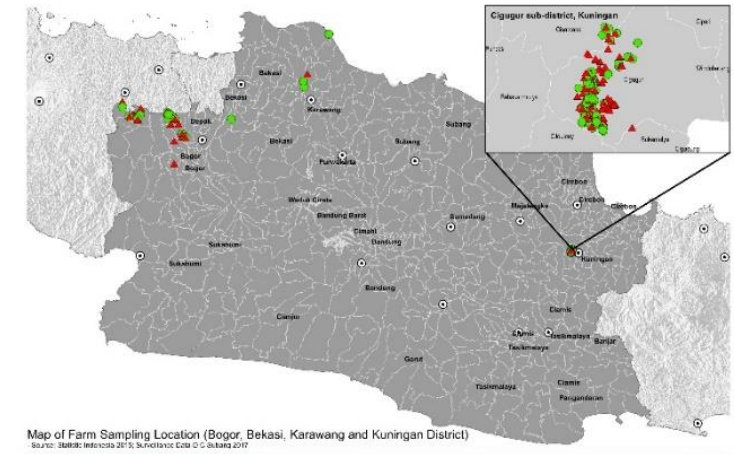

Q)

Fig. 3. Map of pig farm location for profiling and sampling

\section{Data Analysis}

All analyses were performed using four district of study area as the unit of spatial analysis. ArcGIS 10.5 (ESRI, Redlands, California) was used for map figures visualization whereas $\mathrm{R}$ 3.6.1 (www.r-project.org) for statistical analysis. $\mathrm{R}$ is known for the statistical analysis strong point. The data the analyzed using spatstat package which have advantages in analyzing spatial point pattern in 2D. Pig population density was modeled using a function called density which computes an isotropic kernel intensity estimate of the point pattern. This function is also used to calculate the density of pig farms with SIV positive.

The other method that used in this study is spatial autocorrelation. Autocorrelation (whether is spatial or not) is to measure the degree of similarity (correlation) between nearby observations. A commonly used statistic that describes spatial autocorrelation is Moran's I. This method is used to evaluate the SIV distribution pattern (whether is random, clustered or random) and the closest area that has the same value indicates a spatial clustering and also using K-function tool to computes the average number of neighboring features associated with each feature; neighboring features are those closer than the distance being evaluated. As the evaluation distance increases, each feature will typically have more neighbors. If the average number of neighbors for a particular evaluation distance is higher/larger than the average concentration of features throughout the study area, the distribution is considered clustered at that distance [8].

\section{RESULT}

Based on data visualization using kernel density method, it can be seen that in the distance per sq. km obtained 40-49.5 pigs in Bogor, Bekasi and Karawang district marked with dark red on the map. While in Kuningan District, the population density showed more of pigs from 40,000-50,000 per sq $\mathrm{km}$ in red areas. It is indicating that Kuningan district has the highest pig population density compared to Bogor, Bekasi and Karawang districts as shown in Fig. 4. This visualization showed that the risk of transmission of disease between pigs in areas with high density is possible and difficult to prevent its spread and requires proper control. 


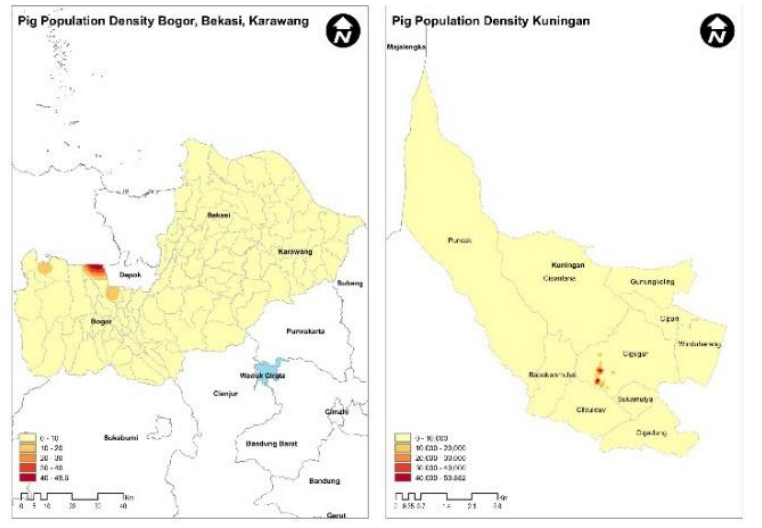

Fig. 4. Map of pig population density in West Java Province

While the results of data visualization using kernel density based on SIV positive ELISA test results on pig farms show that in Bogor, Bekasi and Karawang district found two SIV positive farms per sq. $\mathrm{km}$. while in Kuningan Distrit found more 800 SIV positive farms per sq. $\mathrm{km}$ due to density level of pig farm locations in Kuningan district is higher than Bogor, Bekasi and Karawang District. This means possible if there is a case of SIV on pig farm in Kuningan district can spread easily among pig farms. This can be seen in Fig. 2, 3 and 4 in map using kernel density.

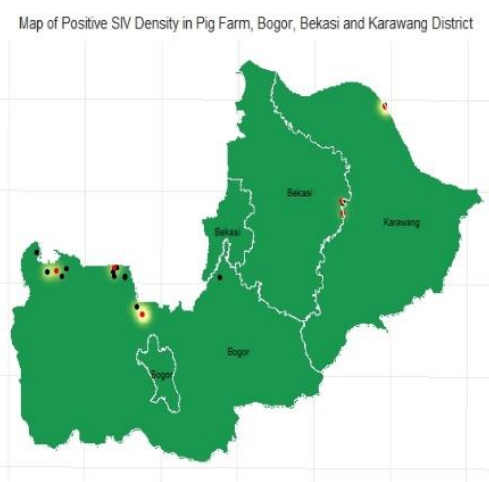

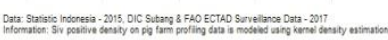

Fig. 5. Map of Positive SIV density in Pig Farm, BoBeKa

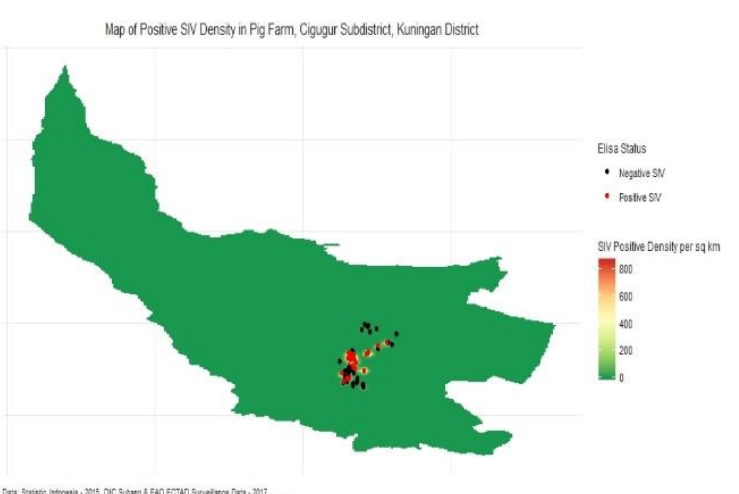

Fig. 6. Map of Positive SIV density in Kuningan District
TABLE 1. MORAN's I INDEX IN BOGOR, BEKASI, KARAWANG AND Kuningan District, West Java Province

\begin{tabular}{|l|l|l|}
\hline \multicolumn{2}{|l|}{$\begin{array}{l}\text { Global Moran's I } \\
\text { Summary in Bogor, } \\
\text { Bekasi and Karawang }\end{array}$} & $\begin{array}{l}\text { Global Moran's I } \\
\text { Summary in Kuningan } \\
\text { District }\end{array}$ \\
\hline Moran's & -0.232534 & 0.374165 \\
\hline Expected & -0.062500 & -0.034483 \\
\hline Variance: & 0.196642 & 0.103360 \\
\hline z-score: & -0.383440 & 1.271083 \\
\hline p-value: & 0.701393 & 0.203699 \\
\hline
\end{tabular}

Based on spatial autocorrelation using Moran's I calculation in table 1, it is found that the moran index value in Kuningan district indicates the value 0 to +1 $(0.374165)$ which means that the location of pig farms in Kuningan district is clustered, while the results of the moran index in Bogor, Bekasi and Kuningan districts indicate the values from 0 to $-1(-0.232534)$ which means that the location of the farm is perfectly dispersed. Using Moran's I spatial autocorrelation can prove that the spatial location of farms in Kuningan district is significantly clustered than Bogor, Bekasi and Kuningan District. The strategy to prevent and control of SIV differ between the clustered locations or dispersed location.
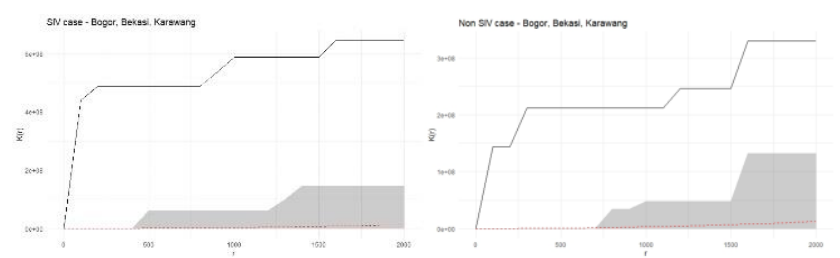

Fig. 7. K-function result SIV case witn non SIV case in BoBeKa District
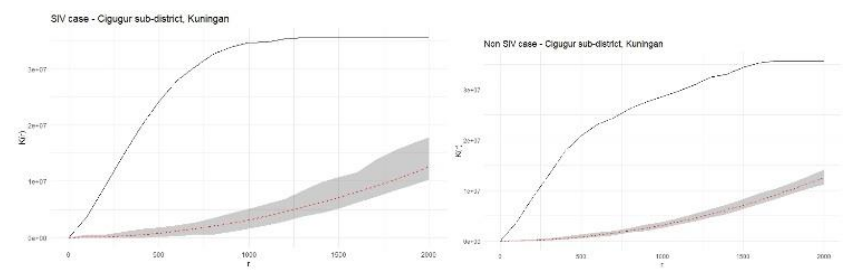

Fig. 8. K-function result SIV case witn non SIV case in Kuningan District

K-function SIV case locations in Kuningan District is greater than the K-function for non-SIV case locations up to 2.000 metres. This means possible if there is a case of SIV on pig farm, more likely to find another SIV-positive case location than a SIV-negative location within 2.000 metres. This information is valuable with what we know about transmission SIV among pig farms. By knowing the seropositive SIV in one pig farm, the control program should extend to 2.000 metres $(2 \mathrm{~km})$ around the positive farm especially in clustered disease area. This information also useful for disease policy makers for disease prevention and control program. If identified a case of SIV positive in 
pig farm location, surveillance efforts should extend to another pig farms a distance of 2.000 metres positive farm especially in clustered disease area.

\section{V.DISCUSSION}

Geographical Information Systems and spatial data analysis with R Studio software are powerful tools for analyzing disease pattern and disease outbreak/cases. Spatial analysis has been used to describe disease pattern and input for disease policy maker for prevent and control the disease. This study using Surveillance laboratory result by DIC Subang from 175 pig farms in four Distrcts. Over $>30 \%$ (54 pig farms) of the pig farms had evidence of SIV positive. Regarding pig management characteristics, mostly pig farm with backyard system. Pig farmers in West Java Province on average have been established for 13 years. The main purpose of raising livestock mostly for trading to consumers and to other pig farmers and slaughtered for pig product. In kernel density, pig farms infected with SIV in Kuningan District showed higher number $>800$ SIV positive farm per sq $\mathrm{km}$ than in Bogor, Bekasi and Kuningan District showed $>2$ SIV positive farm per sq $\mathrm{km}$.

Pig farm in study area selected using Risk based Surveillance where pig farms is divided into high risk farms and low risk farms based on risk factors that support the entry and spread of the disease. The limitation in this study is not all pig farms have been sampled where the SIV virus possibly found in low risk farms. The purpose of surveillance is to detect the presence or absence of SIV in the farm. Pig farm management is conducted by farm owner and few farmers has additional worker. The average total number of workers on each farm is 1 person. Low biosecurity practices in pig farm stimulate SIV transmission between pig farms that can be brought by pig farm owners, workers and direct contact between pigs. There are advantages and limitations in the use of kernel density in every spatial statistic. Kernel density estimation (KDE) is a spatial method that accounts for the location of features (i.e. destinations) relative to each other and offers a more graded measure of destination accessibility [9]. It is important to note that the kernel density estimates were calculated independent of respondent pig farmer. While the estimates are calculated on the basis of destination proximity to each other, the values extracted at each respondent location provide an indication of the proximity and density of destinations in relation to the respondent location. High kernel density estimates indicate high intensity/clustering of destinations that minimize the distance between a respondent's and destinations. Low kernel density estimates indicate negligible, dispersed destinations. Moderate kernel density estimates may indicate dispersed destinations, or they may result when a respondent is located some distance from a set of highly clustered destinations [10]. Introduction of SIV onto a farm is most commonly associated with the introduction of an infected animal [11]. However, no evidence was found of an association between recent movement of animals into the herd and farm status. As well as limitations in the study regarding misclassification, as described above, this lack of association may be due to many farms experiencing persistent infection rather than recent introduction of infection through infected animal. This would also explain the lack of observed association with the frequency of movement of non-farm workers onto farms and into pig buildings in pig farming in West Java Province, which possibly to be a risk factor for virus entry.

Based on spatial autocorrelation result using K-function and Moran's I, Spatial statistic showed Kuningan District clustered. When testing with Ripley's K-function local clustering could be found with a Kernel distance up to 2,000 metres $(2 \mathrm{~km})$ in Kuningan district. No clustering was found applying Moran's I on the spatial distribution in Bogor, Bekasi and Karawang District. there is no spatial autocorrelation between distance and SIV pos cases in Bogor, Bekasi and Karawang District.

\section{CONCLUSION}

GIS software, $\mathrm{R}$ studio and spatial analysis are powerful tool and useful in epidemiology. By using GIS and through $\mathrm{R}$ Studio is easy to determine the spatial relationship between the disease and risk factor that are driver in spread of SIV in clustered farm or dispersed farm location. GIS provides powerful tools for visualization and the analytical approach in research and data exploration. In this spatial analysis study, the use of GIS in understanding the SIV positive farm cases and disease pattern in West Java Province was explored. The study resulted the data was spatially created and visualized to see the low- and high-density area regarding pig population, farm population and SIV positive farm in four districts in West Java Province. Through visualization and spatial database, the number of pig density and SIV positive farm density per sq $\mathrm{km}$ was identified. Our study identified 4 districts in West Java Province with Kuningan District is significant clustered area and has spatial autocorrelation while Bogor, Bekasi and Karawang District are significant dispersed area based on Moran's I index. Our study using k-function found SIV case locations in Kuningan District up to 22.000 metres distance, this support to disease policy maker to conduct surveillance, prevent and control efforts should extend to another pig farms in a distance of 2.000 metres from positive farm in Kuningan District.

\section{RECOMMENDATION}

Effective surveillance strategies for monitoring the development and movement of swine influenza should have a strong focus in densely populated areas. it is necessary to increase awareness to pig farmer and pig collectors from SIV risk that have high risk of transmission between farms. Developing strategies to mitigate disease impact, for example through emergency or preventive vaccination in high risk areas. Kuningan District have disease clustered, the Livestock and Animal Health Services can do targeted intervention in local area and neighbor area within $2.000 \mathrm{~m}$ to prevent and control SIV. 
Pig farmers, pig collectors have to conduct routine check, reporting sick / dead pigs and increased biosecurity in pens to prevent the spread of SIV to other areas. To increase the robustness of the finding it will be more appropriate if we use the outbreak data. This study using surveillance active data.

\section{REFERENCES}

[1] T. Pasma, "Spatial epidemiology of an H3N2 swine influenza outbreak," Can. Vet. J., vol. 49, no. 2, p. 167, 2008.

[2] P. M. Lantos, K. Hoffman, M. Höhle, B. Anderson, and G. C. Gray, "Are people living near modern swine production facilities at increased risk of influenza virus infection?," Clin. Infect. Dis., vol. 63, no. 12, pp. 1558-1563, 2016.

[3] Z. Li, J. Fu, G. Lin, and D. Jiang, "Spatiotemporal Variation and Hotspot Detection of the Avian Influenza A(H7N9) Virus in China, 2013 2017," Int. J. Environ. Res. Public Health, vol. 16, no. 4, p. 648, Feb. 2019.
[4] Https://www.cdc.gov/flu/swineflu/keyfacts

[5] Https://www.oie.int/en/animal-health-in-the-world/animaldisease/Swine-influenza

[6] Bennet R. The 'direct cost' of livestock disease: The development of a system of models for the analysis of 30 endemic livestock diseases in great britain. Journal of Agricultural Economics 2003; 54(1):55-71

[7] Olsen CW, Brammer L, Easterday BC, Arden N, Belay E, Baker I, Cox NJ. Serologic evidence of H1 swine influenza virus infection in swine farm residents and employees. Emerg Infect Dis.2002 Aug;8(8):814-9

[8] https://pro.arcgis.com/en/pro-app/tool-reference/spatial-statistics/hhow-multi-distance-spatial-cluster-analysis-ripl.htm

[9] Smiley MJ, Diez Roux AV, Brines SJ, Brown DG, Evenson KR, Rodriguez DA: A spatial analysis of health-related resources in three diverse metropolitan areas. Health \& Place 2010, 16:885-892

[10]Tania LK, Lukar ET, Rebecca JB, Anne MK:The use of kernel density estimation to examine associatoons between neighborhood destination intensity and walking physical activity. 2015.

[11]Alexander M, Pablo A, Dick P, James W, Susanna W, Ian B Prevalence and risk factor for swine influenza virus infection in the English pig population. Feb 2011 